American J. of Engineering and Applied Sciences 3 (2): 449-453, 2010

ISSN 1941-7020

(C) 2010 Science Publications

\title{
Optimization of Micro Silica in Light Weight Lika Concrete
}

\author{
${ }^{1}$ Alireza Mirza Goltabar Roshan, ${ }^{1}$ Mohammad Bagher Hosseinian, \\ ${ }^{2}$ Hossein Khalilpasha and ${ }^{1}$ Reza Amirpour \\ ${ }^{1}$ Department of Civil Engineering, Babol Noshirvani University of Technology, Iran \\ ${ }^{2}$ Department of Structures and Materials, Faculty of Civil Engineering, \\ University Technology Malaysia, Malaysia
}

\begin{abstract}
Problem statement: In this article, special kind of light weight aggregate named lika had been studied. Approach: The aim of this research was first, to achieve the best mix design of light weight concrete which could be in light weight concrete category and second, by applying the first part gain the main reason of this research which was finding the optimized amount of Micro Silica in a light weight lika concrete. Results: Experimental results had been compared with theoretical viewpoints to reach the properties of the optimized concrete with lika. Conclusion: It is concluded that we can get to a light weight structure concrete applying light aggregate of lika.
\end{abstract}

Key words: Micro silica, light weight, concrete, lika

\section{INTRODUCTION}

Micro Silicic is one of the materials used to make a light weight concrete. Before, it has been used instead of cement to reduce the amount of cement in concrete because of the expenses of cement but since the price of this material has increased in most of the countries it is not economical to apply it as a supersede of cement. Silica is more usual these days as an additional material to obtain special properties of concrete. Microsilica is one of the most active materials among all puzolanic materials. You can reach to pozolani properties sooner in Microsilica than other pozolanic materials. According to its shape and size, micro silica can be used as an active fillet material in concrete. Because of high degree of pozolanic activation, micro silica can convert useless crystallic Hydroxide Calcium to gel. It means that Micro silica combines with calcium hydroxide and converts it to stable calcium Silicate combinations. The concrete mixtures with microsilis have great adhesion, the reason is increasing the contact points of the solid particles and therefore they can be used in pumping. If microsilis is used as an additional material, it does not have harmful effect on the short term strength of concrete meanwhile it has a great effect in increasing the curing of concrete during 3-28 days. The aim of this research is finding the optimized amount of Micro Silica in a light weight lika concrete.

The effects of microsilis and variables: Microsilis has many effects on concrete including: (1) preventing waterlog and separation of aggregates (2) plastic shrinkage (3) absorption (4) effect of microsilis on the concrete water content (5) pumping capability.

Many researches were done for study of lightweight concrete that some of them are in below.

Notwithstanding the relatively low strength of lightweight aggregates, this investigation reports results of a study undertaken to develop high strength lightweight concretes using a Canadian lightweight aggregate. A series of seven concrete mixtures involving 25 batches were made. The cement, or cements, fly ash and silica fume content of the mixtures ranged from $300-635 \mathrm{~kg} \mathrm{~m}^{-3}$. From the results of this investigation, it is concluded that high strength concretes with densities of less than $2000 \mathrm{~kg} \mathrm{~m}^{-3}$ can be made with or without the use of mineral admixtures, but the use of super plasticizers is mandatory. The highest compressive strength achieved was $66.5 \mathrm{MPa}$ at 365 days for a cementations content of $638 \mathrm{~kg} \mathrm{~m}^{-3}$. The 28 day splitting-tensile strengths obtained were of the order of 3.5 MPa. The freezing and thawing tests performed in accordance with ASTM C 666 Procedure $\mathrm{A}$, freezing in water and thawing in water, indicated excellent frost resistance of concrete with durability factors generally greater than 90 (Wilsona and Malhotrab, 1988).

Properties of high strength tuff lightweight aggregate concrete (Smadi and Migdady, 1991), characteristics of high strength ber reinforced lightweight aggregate concrete (Kayali et al., 2003),

Corresponding Author: Alireza Mirza Goltabar Roshan, Department of Civil Engineering,

Babol Noshirvani University of Technology, Iran 
Strength and durability of lightweight concrete (Haque et al., 2004) and Optimization of using lightweight aggregates (Akcay and Tasdemira, 2009) are studied by other researcher and in this research, effects of microsilis are studied.

\section{MATERIALS AND MATHODS}

Consumable materials: The cement used in this research is portlant cement Type II produced by Neka factory in Iran which has special weight of $3150 \mathrm{~kg} \mathrm{~m}^{-3}$ and initial absorption of 175 minutes and second absorption of $230 \mathrm{~min}$ and compressive strength and 7 and 28 days equal to $17.4,21.4$ and $34.1 \mathrm{MPA}$.

Gravel: The gravel used is mountain gravel with maximum size of $9.5 \mathrm{~mm}$.

Sand: The used sand is river sand that has been modified to 3 in toughness. Aggregation is according to ASTM standard and SE $=70$.

Lika: The provide Lika has been supplied by a factory in Saveh in Iran with 0-3 mm fine aggregate.

Mirosilis: The applied microsilis has a special weight of $2200 \mathrm{Kg} \mathrm{m}^{-3}$ and Belin $20.2 \mathrm{~m}^{2} \mathrm{~g}^{-1}$. This additional has been used without and used dry sand as a percentage of cement added to the concrete mixture.

Ultra liquid: At this research an ultra liquid with commercial brand of PCE produced by Van chemist factory in Iran has been used.

Water: Usually any kind of water that is drinkable without any special smell and taste can be used as mixture water in concrete construction. At this research regular water are obtained from the city water network (ACI Committee, 1984).

Table 1: Mix design groups

\begin{tabular}{lllclll}
\hline $\begin{array}{l}\text { Mix } \\
\text { group }\end{array}$ & $\begin{array}{l}\text { Lika } \\
(\%)\end{array}$ & Water & $\begin{array}{c}\text { Ultra } \\
\text { liquid }\end{array}$ & Gravel & Sand & Lika \\
\hline $\mathrm{G}_{\mathrm{A}}$ & 40 & 2.778 & 7.5 & 2.317 & 5.56 & 3.707 \\
$\mathrm{G}_{\mathrm{B}}$ & 50 & 2.778 & 7.5 & 2.317 & 4.633 & 4.633 \\
$\mathrm{G}_{\mathrm{C}}$ & 60 & 2.778 & 15.0 & 2.317 & 3.707 & 5.560 \\
\hline
\end{tabular}

Final mix design: The amount of used cement is 500 $\mathrm{Kg}, \mathrm{W} / \mathrm{C}=0.5$, special weight equal to $1800 \mathrm{Kg} \mathrm{m}^{-3}$ with $20 \%$ of gravel aggregate, $40 \%$ sand aggregate and $40 \%$ Lika. At these designs the same rate of decrees in sand has been added to increase in lika. It has adequate design either in 7 and 28 days strength or in special weight. After finding the correct mix design the experiments have been done in $3 \mathrm{mix}$ design groups that are indicated in Table 1.

Construction and curing of samples: At this research 21 mix design in 3 groups $\left(G_{A}, G_{B}, G_{C}\right), 7$ in each group.

Group $\mathbf{G}_{\mathbf{A}}$ : Includes samples with lika amount of $40 \%$ fine aggregate and microsilis change amounts of 0,5 , $10,15,20,25$ and $30 \%$ of cement weight.

Group $\mathbf{G}_{\mathbf{B}}$ : Includes samples with lika amount of $50 \%$ fine aggregate and microsilis change amounts of 0,5 , $10,15,20,25$ and $30 \%$ of cement weight.

Group $\mathbf{G}_{\mathbf{C}}$ : Includes samples with lika amount of $60 \%$ fine aggregate and microsilis change amounts of 0,5 , $10,15,20,25$ and $30 \%$ of cement weight.

It should be mentioned that the microsilis would be exchanged with cement in mix design of all cements are 500 for all mix designs and all mix designs are constructed in two step with cubic sample $10 \times 10 \times 10$ (12 sample for each design) and have been experimented. The curing method is to take out the samples from that After $24 \mathrm{~h}$ of construction and curried in water 7 and 28 days.

Sample experiments: According to the importance of compression strength of concrete, the samples have been experimented after 7 and 28 days with compressive jacks.

\section{RESULTS}

Results of experiments: Table 2 is a sample of results of the experiments which indicates the results for Group $\mathrm{G}_{\mathrm{A}}\left(\mathrm{G}_{\mathrm{A}}\right)$ with $0 \%$ of microsilis and $40 \%$ of Lika and $\mathrm{S}$ shows the standard deviation.

Table 2: Mechanical properties of $\mathrm{GA}_{\mathrm{o}} \mathrm{L} 40$

\begin{tabular}{|c|c|c|c|c|c|c|c|c|c|}
\hline \multicolumn{3}{|c|}{ Wet special mass } & \multicolumn{2}{|l|}{$\mathrm{W}$} & \multicolumn{4}{|c|}{ Strength $\left(\mathrm{kg} \mathrm{cm}^{-2}\right)$} & \multirow[b]{2}{*}{ Sample } \\
\hline Average & 28 & 7 & 28 & 17 & Average & 28 & Mean & 7 & \\
\hline \multirow{6}{*}{$\begin{array}{l}1814 \\
S=5.58\end{array}$} & 1820 & 1815 & 1809 & 1806 & \multirow{6}{*}{$\begin{array}{l}319 \\
S=8.80\end{array}$} & 315 & \multirow{6}{*}{$\begin{array}{l}247 \\
S=3.67\end{array}$} & 250 & 1 \\
\hline & 1808 & 1818 & 1786 & 1818 & & 318 & & 245 & 2 \\
\hline & 1818 & 1820 & 1803 & 1892 & & 322 & & 240 & 3 \\
\hline & 1808 & 1818 & 1790 & 1802 & & 306 & & 250 & 4 \\
\hline & 1815 & 1803 & 1806 & 1799 & & 326 & & 250 & 5 \\
\hline & 1809 & 1812 & 1791 & 1801 & & 328 & & 246 & 6 \\
\hline
\end{tabular}


Study the results of the experiments: The experiments have been done in the Laboratory of Noshirvani University of technology and the results have been categorized in 3 types to conclude the results better.

Study on group $G_{A}$ including samples of $40 \%$ lika fine aggregate: The results of the $G_{A}$ group can be discussed in two categories.

The relation between 7 and 28 days strength with increasing the amounts of microsilis: These groups of mix designs have the greatest value of strength among all experiments and the maximum 7 day in this group belongs to $\mathrm{G}_{\mathrm{Ao}} \mathrm{L} 40$ with strength of $301 \mathrm{Kg} \mathrm{cm}^{-2}$ with microsilis of $15 \%$ weight of cement and the maximum 28 days belong to $\mathrm{G}_{\mathrm{A} 15} \mathrm{~L} 40$ with strength of $446.5 \mathrm{Kg}$ $\mathrm{cm}^{-2}$ with microsilis of $15 \%$ weight of cement. The increasing rate from 7-28 days is between $29-48 \%$. Figure 1 shows the strength of concrete for this group.

Relation between microsilis and special weight: Figure 2 shows that when the mount of microsilis increase the amount of special weight rises. The maximum value belongs to $\mathrm{G}_{\mathrm{A} 30} \quad \mathrm{~L}_{40}$ with $30 \%$ microsilis weight of cement. At this group the rate of increasing the special weight is $0.36-2.4 \%$.

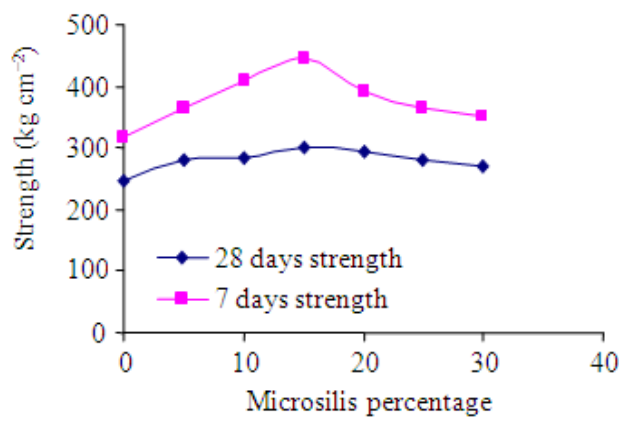

Fig. 1: 7 and 28 days strength of samples by increasing microsilis

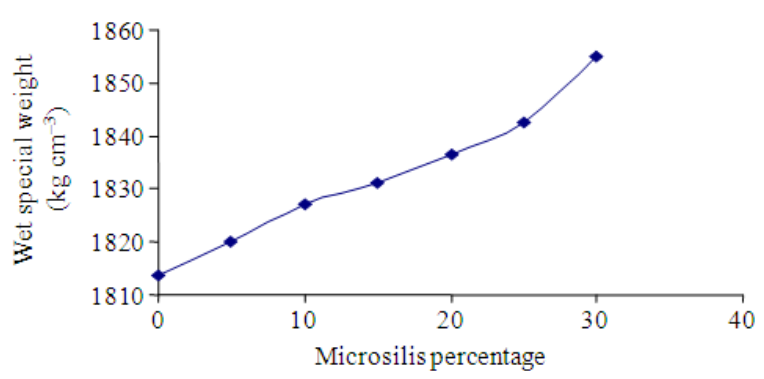

Fig. 2: Special weight and microsilis percentage
Study on group $\mathbf{G}_{\mathrm{B}}$ including samples of $50 \%$ lika fine aggregate: The results of the $G_{A}$ group can be discussed in two categories.

The relation between 7 and 28 days strength with increasing the amounts of microsilis: The most 7 days strength in this group belongs to mix design $G_{B 15} L_{50}$ with compression strength of $324.7 \mathrm{Kg} \mathrm{cm}^{-2}$ with $15 \%$ microsilis. The most 28 days strength of this group goes to $\mathrm{G}_{\mathrm{B} 15} \mathrm{~L}_{50}$ with compression strength of $389.1 \mathrm{Kg} \mathrm{cm}^{-2}$ with $15 \%$ microsilis of cement. The increase rate is $17-30 \%$. Also, at this group the 7 days mix design had $23.5 \%$ increase and 28 days $36.6 \%$ increase in strength rather than light weight concrete without microsilis. Figure 3 shows the increase in the compression strength of group $\mathrm{G}_{\mathrm{B}}$.

Relation between microsilis and special weight: The biggest value of special weight at this group belongs to $G_{B 30} L_{50}$ with $30 \%$ microsilis in cement weight. At this group the rate of increasing the special weight is $0.52-2.42 \%$.

Study on group $\mathbf{G}_{\mathrm{C}}$ including samples of $\mathbf{5 0 \%}$ lika fine aggregate: The results of the $G_{A}$ group can be discoursed in two categories.

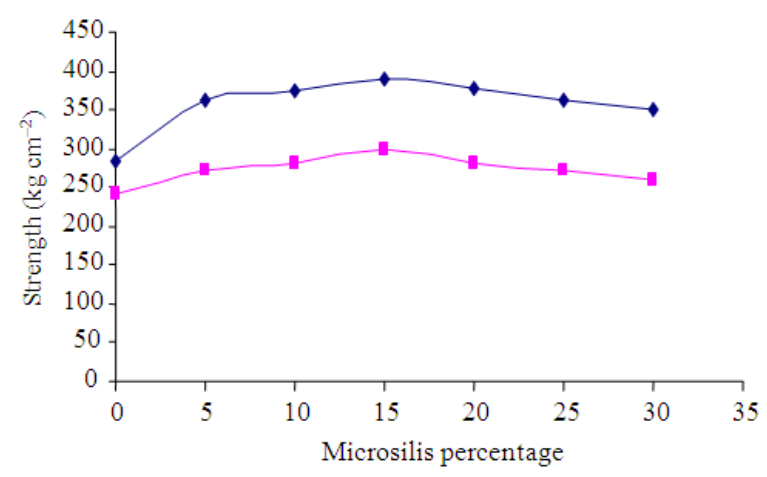

Fig. 3: 7 and 28 days strength with different microsilis

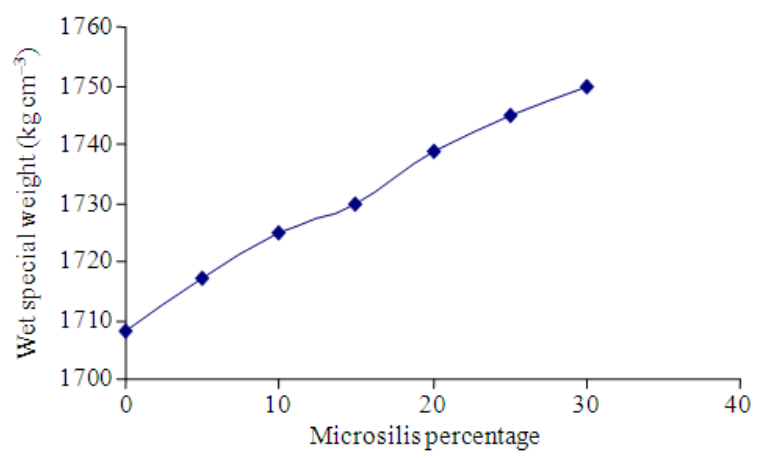

Fig. 4: Special weight and microsilis percentage 
The relation between 7 and 28 days strength with increasing the amounts of microsilis: At this group the most 7 days strength belongs to mix design $\mathrm{G}_{\mathrm{C} 15} \mathrm{~L}_{60}$ with compression strength of $196.7 \mathrm{Kg} \mathrm{cm}^{-2}$ with $15 \%$ microsilis. As it can be seen this group has less strength compare with other two groups. The reason is because this group includes $60 \%$ lika which reduces the special weight gradually. The concrete produced by this design is purposive. The most 28 days strength of this group goes to $\mathrm{G}_{\mathrm{C} 15} \mathrm{~L}_{50}$ with compression strength of $377 \mathrm{Kg} \mathrm{cm}$ cm $^{-2}$ with $15 \%$ microsilis of cement. The increase rate is $13-46 \%$. Also, at this group the 7 days mix design had $34.9 \%$ increase and 28 days $72 \%$ increase in strength rather than light weight concrete without microsilis. Figure 5 shows the increase in the compression strength of group $\mathrm{G}_{\mathrm{C}}$.

Relation between microsilis and special weight: The biggest value of special weight at this group belongs to $\mathrm{G}_{\mathrm{C} 30} \mathrm{~L}_{50}$ with $30 \%$ microsilis in cement weight (Fig. 6). At this group the rate of increasing the special weight is $0.26-1.26 \%$.

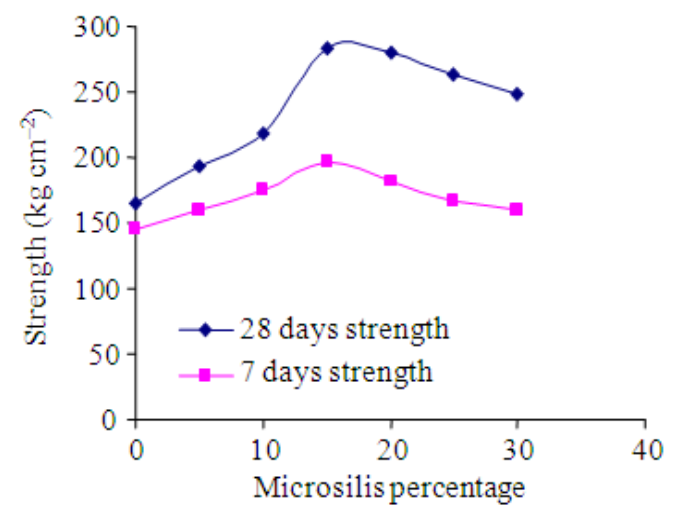

Fig. 5: 7 and 28 days strength with different microsilis

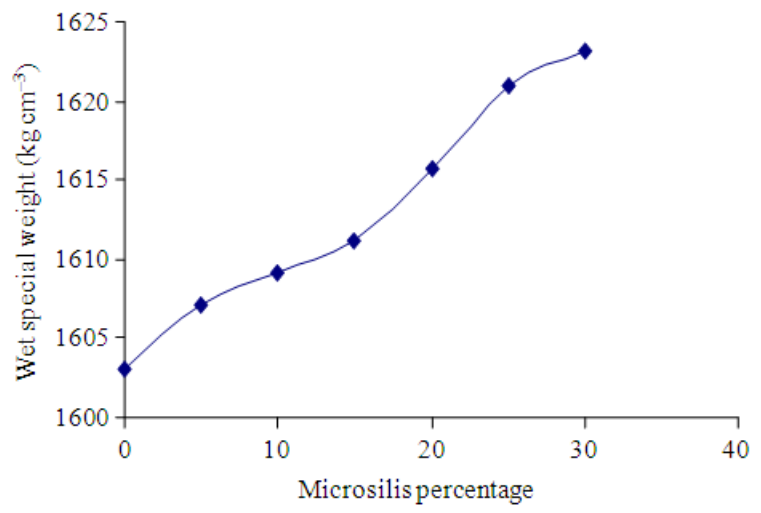

Fig. 6: Special weight and microsilis percentage
Comparison of 7 days strength of different 3 groups: The maximum values of 7 days compression strength of groups $\mathrm{G}_{\mathrm{A}}, \mathrm{G}_{\mathrm{B}}, \mathrm{G}_{\mathrm{C}}$ are $301,299.3$ and $196.7 \mathrm{~kg} \mathrm{~cm}^{-2}$. According to the Fig. 7 the groups $G_{A}, G_{B}$ have almost close values but have great difference with group $\mathrm{G}_{\mathrm{C}}$ that the graph shows about $1 \%$ difference between these two groups that could be negligible thus group can be a better design for light weight concrete because it has less special weight due to more lika (from 40-50\%). But there is a big difference about $34 \%$ between the 7 days strength of groups $G_{B}$ and $G_{C}$ which means that the strength of the concrete would decrease dramatically by adding more lika from $\mathrm{G}_{\mathrm{B}}$ to $\mathrm{G}_{\mathrm{C}}$. Also there is not that much different in strength rise rate from $0-15 \%$ of microsilis and decrease from $15-30 \%$.

Comparison of 28 days strength of different 3 groups: The maximum values of 28 days compression strength of groups $G_{A}$ is 446.5 for group $G_{B}$ is 389.1 and for $G_{C}$ is $284 \mathrm{k} \mathrm{cm}^{-1}$. According to Fig. 8 the difference of the compression strength of the groups $\mathrm{G}_{\mathrm{A}}, \mathrm{G}_{\mathrm{B}}$ is not very much but again has great difference with group $G_{C}$ that the graph shows about $15 \%$ difference between these two groups and $27 \%$ from $G_{B}$ to $\mathrm{G}_{\mathrm{C}}$. Which conduct to the same conclusion as 8-4. Also strength rise rate from $0-15 \%$ of microsilis is rapid but decrease from $15-30 \%$ slow.

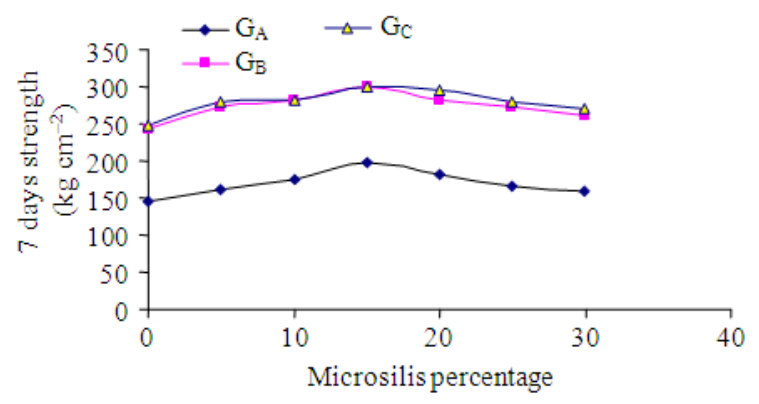

Fig. 7: Comparison of 7 days strength of groups

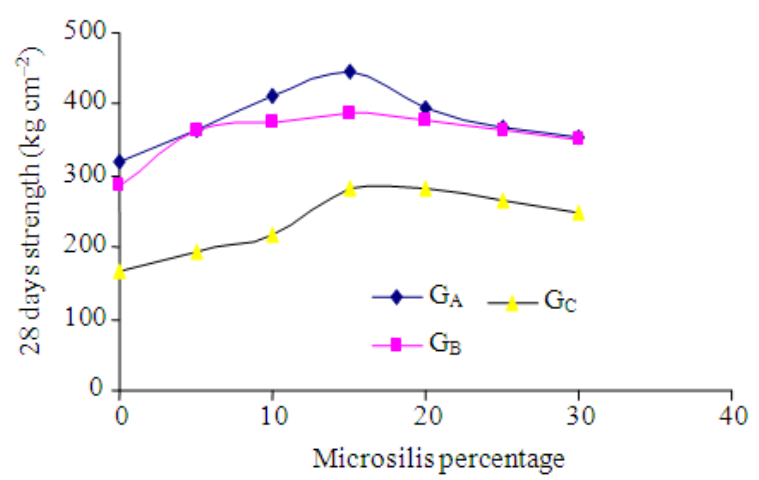

Fig. 8: Comparison of 28 days strength of groups 


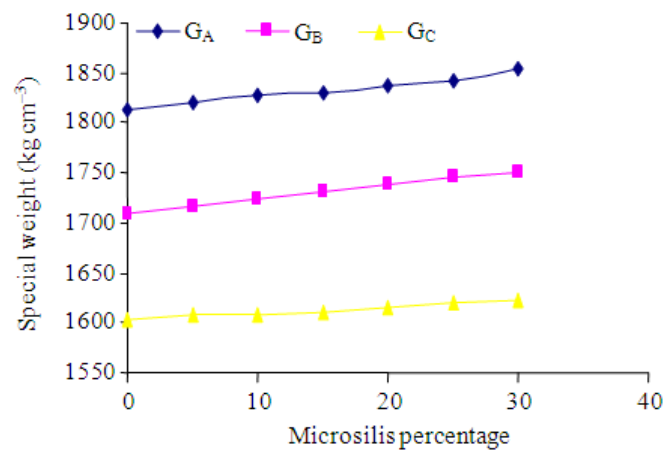

Fig. 9: Comparison of special weight of groups

Comparison of special weight increase of different 3 groups: Figure 9 indicates a little increase in special weight for all groups. The amount varies from 0.26$2.42 \%$ which is negligible. Group $\mathrm{G}_{\mathrm{C}}$ experiments the least increase that is from $0.26-1.26 \%$. This amount is equal for groups $G_{A}, G_{B}$.

\section{DISCUSSION}

Adding 15-30\% microsilis of the weight of cement to the mix design would decrease the compression strength of concrete. The reason is, when we add microsilis we reduce the cement volume at the same rate and while the amount of microsilis increases to 20$30 \%$, the amount of the cement that has been eliminated from the mix design becomes more than the performance of the cement and cement looses its performance.

The scratches of 7-28 days strength of the groups are as follows:

- Group $\mathrm{G}_{\mathrm{A}}$ increasing in strength between $29-48 \%$

- Group $\mathrm{G}_{\mathrm{B}}$ increasing in strength between $29-48 \%$

- Group $\mathrm{G}_{\mathrm{C}}$ increasing in strength between $29-48 \%$

- The rate of increase and decrease in 7 days strength is almost the same and with the same declination

- The rate of increasing the 28 days strength is different and it is rapidly from $0-15 \%$ and slowly in decreasing from $15-30 \%$

- The special weight of the concrete will rise with adding the percentage of microsilis. This rise is variable from $0.32-4.2 \%$

\section{CONCLUSION}

To conclude, the following results could be obtained by the whole process of experimental and data analysis:

- We can get to a light weight structure concrete applying light aggregate of lika

- To construct light weight concrete using lika, it is advantageous to use microsilis too because by using a little microsilis the compression strength would increase a lot

- Increasing the amount of microsilis the strength of concrete would increase too up to the amount of additional microsilis in mix design

- By adding about $0-15 \%$ microsilis of the weight of cement, to the mix design, the compression strength of the concrete would increase the reason can be:

- Microsilis aggregate are finer than cement aggregate and would fill the porous medias

- it is because of the chemical activity of microsilis that converts the hydroxide calcium which is the weakness of concrete to the stabilized silicate calcium

- Adding 15-30\% microsilis of the weight of cement to the mix design would decrease the compression strength of concrete. The reason is, when we add microsilis we reduce the cement volume at the same rate and while the amount of microsilis increases to $20-30 \%$, the amount of the cement that has been eliminated from the mix design becomes more than the performance of the cement and cement looses its performance

\section{REFERENCES}

ACI Committee, 1984. Guide for structural lightweight aggregate concrete. Part 1: Materials and General Properties of Concrete, ACI Committee 213.

Akcay, B. and M.A. Tasdemira, 2009. Optimization of using lightweight aggregates in mitigating autogenous deformation of concrete. Construct. Build. Mater. 23: 353-363. DOI: 10.1016/j.conbuildmat.2007.11.015

Bamforth, P.B., 1980. Institute measurement of the effect of partial Portland cement replacement using fly ash or ground granulated blast furnace Salg on the performance of mass concrete. Proc. Inst. Civil Eng., 69: 777-800. DOI: 10.1680/iicep.1980.2377

Haque, M.N., H. Al-Khaiat and O. Kayali, 2004. Strength and durability of lightweight concrete. Cem. Concr. Comp., 26: 307-314. DOI: 10.1016/S0958-9465(02)00141-5

Kayali, O., M.N. Haque and B. Zhu, 2003. Some characteristics of high strength fiber reinforced lightweight aggregate concrete. Cem. Concr. Comp., 25: 207-213. DOI: 10.1016/S0958-9465(02)00016-1

Smadi, M. and E. Migdady, 1991. Properties of high strength tuff lightweight aggregate concrete. Cem. Concr. Comp., 13: 129-135. DOI: 10.1016/09589465(91)90008-6

Wilsona, H.S. and V.M. Malhotrab, 1988. Development of high strength lightweight concrete for structural applications. Int. J. Cem. Comp. Lightweight Concr., 10: 79-90. DOI: 10.1016/0262-5075(88) 90034-6 